Carta al editor/ Letters to the editor

\title{
Balantidium nawaraoi, un nuevo ciliado en humanos
}

\section{Balantidium nawaraoi, a new ciliate in humans}

\author{
Traviezo-Valles, Luis [D 0000-0003-4544-6965]। \\ 'Universidad Centroccidental Lisandro Alvarado, Barquisimeto, Venezuela. \\ $\bowtie$ luisetraviezo@hotmail.com
}

Recibido: 25/10/2021;

Aceptado: 29/II/202I;

Publicado: 20/01/2022

Cómo citar / Citation: Traviezo-Valles, L. (2022). Balantidium nawaraoi, un nuevo ciliado en humanos. Revista de Veterinaria y Zootecnia Amazónica, 2(I), e223. https://doi.org/ I0.5 I 252/revza.v2i I.223

Señor editor. Leyendo con atención un artículo de su revista intitulado "Prevalencia coprológica de parásitos gastrointestinales en humanos y porcinos de crianza de traspatio del distrito de Zapatero, San Martín" el cual reporta solo en porcinos 0,57\% de prevalencia para Balantidium coli y señala el grado de este y otros enteroparásitos en cerdos como de importancia en la transmisión al hombre (I), al respecto quisiera agregar lo siguiente:

El único ciliado descrito para el hombre era Balantidium coli (Neobalantidium coli), causante de la balantidiasis o balantiosis (Figura I), pero recientemente se describió en la Revista Médica Sinergia 6 (2) e637, 202I, un nuevo protozoario colonizando intestino humano. Se trata de Balantidium nawaraoi (Neobalantidium nawaraoi) $(2,3)$.

Figura I. Trofozoito de Balantidium coli en mucosa de intestino grueso de cerdo. Coloración de Hematoxilina y Eosina. Aumento de 400X.

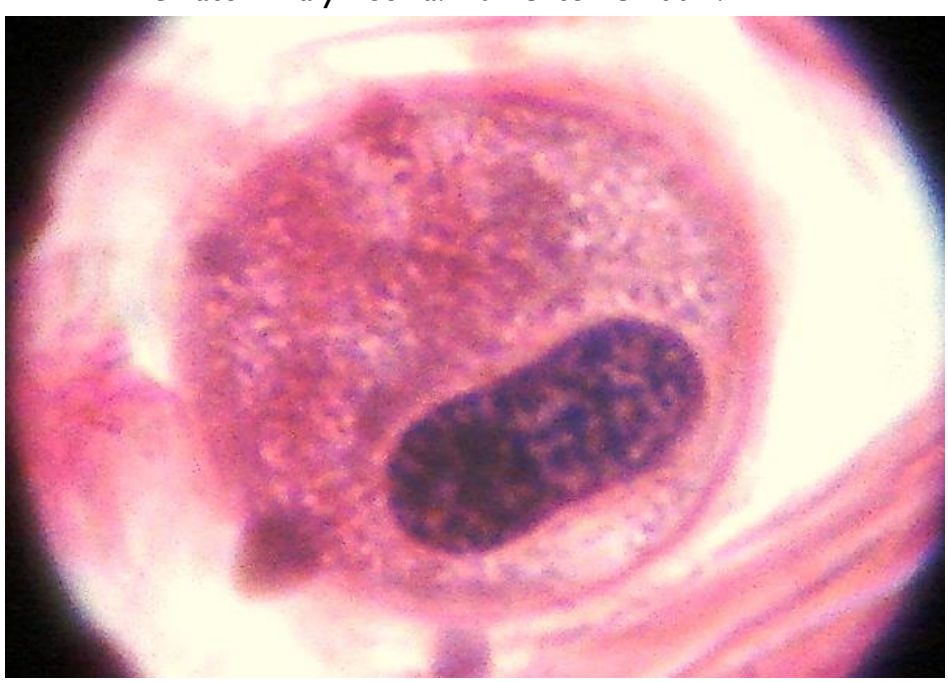

Fuente: Microfotografía del autor.

Esta nueva especie de Balantidium fue encontrada en pacientes de la etnia indígena warao, específicamente de la comunidad selvática de Nabasanuka (LN 0908'I I,9” y LO 06 I 03’3I,2”) en el delta del Río Orinoco, el río más largo y de mayor caudal de Venezuela, el cual nace en la selva amazónica al Sur del país y desemboca en el océano Atlántico en el noreste de Venezuela, 
específicamente en el estado Delta Amacuro (Figura 2), a relativamente poca distancia de la Isla de Trinidad y de la República de Guyana (2).

Figura 2. Localización de la población de Nabasanuka en el noreste del estado Delta Amacuro, Venezuela.

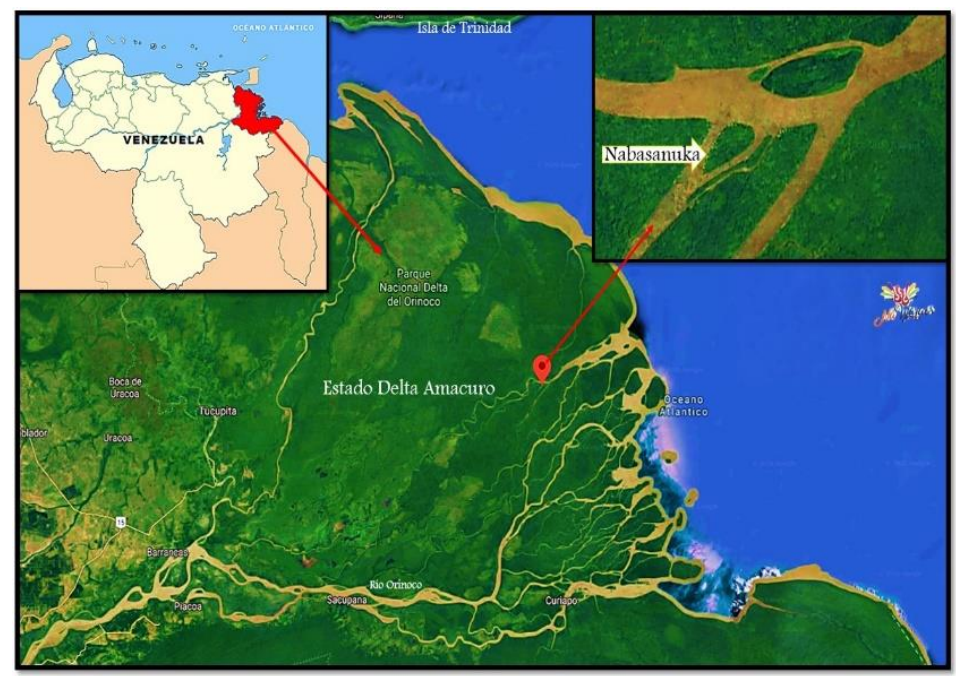

Fuente: Composición fotográfica del autor.

A esta comunidad warao solo se puede llegar por vía fluvial en largos recorridos en lanchas que pueden durar hasta 14 horas, saliendo desde el pequeño puerto más cercano o por via aérea solo con el auxilio de un helicóptero.

Este nuevo ciliado se encontró en pacientes humanos poliparasitados y con sintomatología gastrointestinal y se diferencia morfológicamente de Balantidium coli en que sus trofozoitos eran más alargados y elipsoidales, aplanados y densamente ciliados. Presentaban una longitud entre $87 \mu \mathrm{m}$ a $97 \mu \mathrm{m}$, con una anchura que fluctuaba entre los $38 \mu \mathrm{m}$ a $42 \mu \mathrm{m}$ (Figuras 3, 4, 5 y 6 ).

Figura 3. Trofozoito de Balantidium nawaraoi junto a un huevo de Ascaris lumbricoides, ambos en solución salina isotónica $0,85 \%$. Aumento de $400 X$.

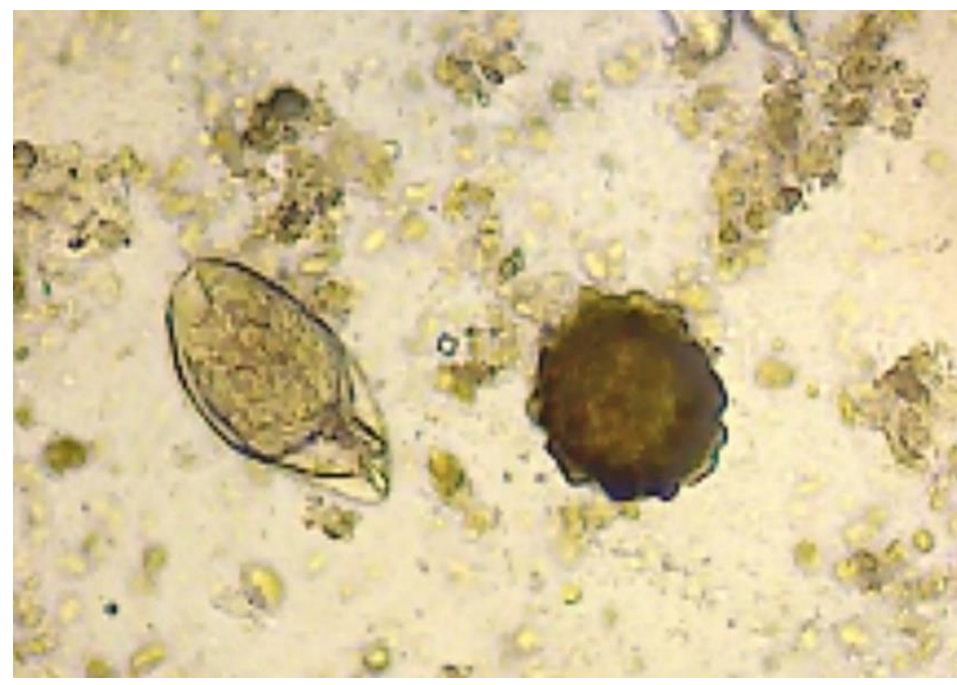

Fuente: Composición fotográfica del autor. 
Figura 4. Huevo de Ascaris lumbricoides, junto a un trofozoito de Balantidium nawaraoi, ambos en solución salina isotónica $0,85 \%$. Aumento de $400 X$.

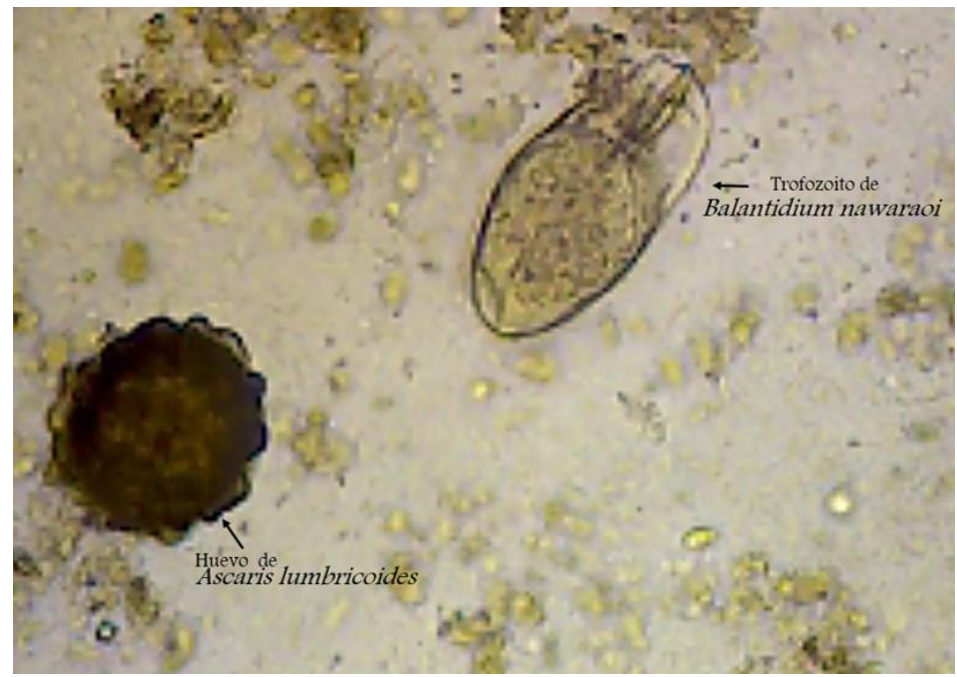

Fuente: Composición fotográfica del autor.

Figura 5. Trofozoito de Balantidium nawaraoi en solución salina isotónica $0,85 \%$. Aumento de $400 X$.

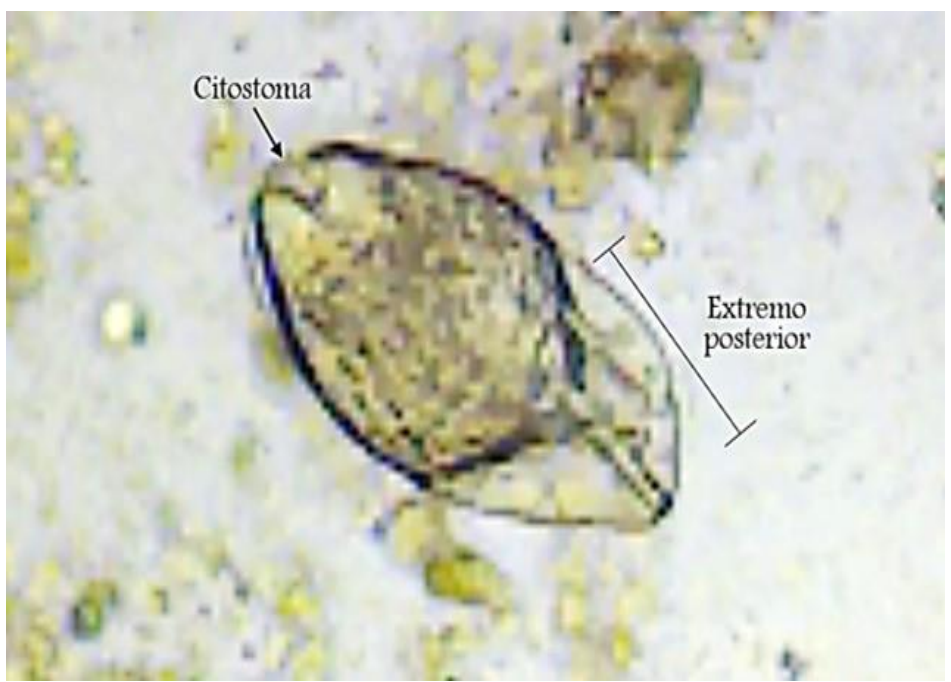

Fuente: Composición fotográfica del autor. 
Figura 6. Trofozoito de Balantidium nawaraoi en solución salina. Se indica el citostoma y los cilios. Aumento de 400X.

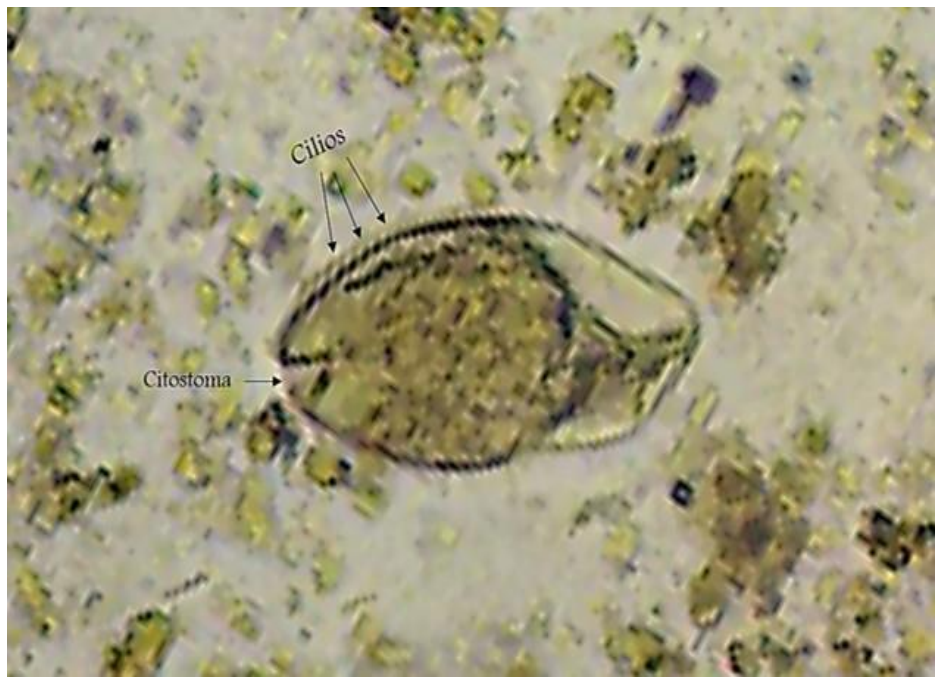

Fuente: Composición fotográfica del autor.

En el extremo anterior se observó un peristoma (vestíbulo bucal) en forma de "V" más ancho o abierto que B. coli, de entre $12 \mu \mathrm{m}$ y $16 \mu \mathrm{m}$ de largo y entre $18 \mu \mathrm{m}$ a $22 \mu \mathrm{m}$ de ancho lo que representa $\mathrm{I} / 6$ de la longitud total del nuevo ciliado (2).

La característica más relevante para diferenciarlo fue su extremo posterior más angosto, con su tercio posterior (TP) con una estructura aparentemente hueca y en espiral más transparente que el resto del cuerpo, la cual es inexistente en Balantidium coli y en otras especies de este género. Esta estructura TP mide entre $26 \mu \mathrm{m}$ a $30 \mu \mathrm{m}$ de largo, con un ancho entre los $27 \mu \mathrm{m}$ y $3 \mathrm{I} \mu \mathrm{m}(2)$.

Se hizo todo lo posible por acabar con el foco humano de este nuevo protozoario para evitar que se extendiera a otras comunidades indígenas, pero se desconoce el o los posibles reservorios animales que pudieran mantener latente la transmisión. Se sospecha de Tayassu pecari como el posible reservorio mamífero, en concordancia con el cerdo que funciona como el reservorio animal para Balantidium coli.

Se continúa con los estudios para ensamblar el ciclo completo de este nuevo parásito, sus elementos epidemiológicos y su papel patogénico, pero es importante tenerlo en cuenta en lo adelante en todos los estudios de parasitosis intestinal en animales y en humanos habitantes de la cuenca amazónica.

\section{Referencias bibliográficas}

I. Puicón V, López-Flores A, Fabian-Dominguez F, Sánchez-Cárdenas H. Prevalencia coprológica de parásitos gastrointestinales en humanos y porcinos de crianza de traspatio del distrito de Zapatero, San Martín. Revista de Veterinaria y Zootecnia Amazónica. 202I; I(I): 4-I4. https://doi.org/I0.5I252/revza.vlil.I27 
2. Traviezo Valles L. Balantidium nawaraoi n. sp., en la comunidad warao de Nabasanuka. Venezuela. Revista Médica Sinergia. 2021 ; 6 (2): e637. https://doi.org//0.31434/rms.v6i2.637

3. Cazorla-Perfetti D. Balantidium coli, Neobalantidium coli $O$ Balantioides coli? Protozoario, Balantidiosis o Balantiosis? Rev SABER. 2018; 30: 413-4I7.

\section{Conflicto de intereses}

Ninguna. 